\title{
COVID-19 in breast cancer patients: a cohort at the Institut Curie hospitals in the Paris area
}

Perrine Vuagnat ${ }^{1,2,3}$ (D) Maxime Frelaut ${ }^{4}$, Toulsie Ramtohul ${ }^{5}$, Clémence Basse ${ }^{2,3}$, Sarah Diakite ${ }^{2,3}$, Aurélien Noret ${ }^{2,3}$, Audrey Bellesoeur ${ }^{2,3}$, Vincent Servois ${ }^{5}$, Delphine Hequet ${ }^{6}$, Enora Laas ${ }^{6}$, Youlia Kirova $^{7}$, Luc Cabel ${ }^{2,3}$, Jean-Yves Pierga ${ }^{2,3,8}$, Institut Curie Breast Cancer and COVID Group, Laurence Bozec ${ }^{2,3+}{ }^{+}$, Xavier Paoletti ${ }^{1,9 \dagger}$, Paul Cottu $2,3+$ and François-Clément Bidard ${ }^{1,2,3^{*}+}$

\begin{abstract}
Background: Cancer patients have been reported to be at higher risk of COVID-19 complications and deaths. We report the characteristics and outcome of patients diagnosed with COVID-19 during breast cancer treatment at Institut Curie hospitals (ICH, Paris area, France).

Methods: An IRB-approved prospective registry was set up at ICH on March 13, 2020, for all breast cancer patients with COVID-19 symptoms or radiologic signs. Registered data included patient history, tumor characteristics and treatments, COVID-19 symptoms, radiological features, and outcome. Data extraction was done on April 25, 2020. COVID-19 patients were defined as those with either a positive RNA test or typical, newly appeared lung CT scan abnormalities.
\end{abstract}

Results: Among 15,600 patients actively treated for early or metastatic breast cancer during the last 4 months at $\mathrm{ICH}, 76$ patients with suspected COVID-19 infection were included in the registry and followed. Fifty-nine of these patients were diagnosed with COVID-19 based on viral RNA testing $(N=41)$ or typical radiologic signs: $37 / 59(63 \%)$ COVID-19 patients were treated for metastatic breast cancer, and 13/59 (22\%) of them were taking corticosteroids daily. Common clinical features mostly consisted of fever and/or cough, while ground-glass opacities were the most common radiologic sign at diagnosis. We found no association between prior radiation therapy fields or extent of radiation therapy sequelae and extent of COVID-19 lung lesions. Twenty-eight of these 59 patients (47\%) were hospitalized, and $6(10 \%)$ were transferred to an intensive care unit. At the time of analysis, 45/59 (76\%) patients were recovering or had been cured, 10/59 (17\%) were still followed, and 4/59 (7\%) had died from COVID-19. All 4 patients who died had significant non-cancer comorbidities. In univariate analysis, hypertension and age (> 70) were the two factors associated with a higher risk of intensive care unit admission and/or death.

(Continued on next page)

\footnotetext{
* Correspondence: fcbidard@curie.fr

'Laurence Bozec, Xavier Paoletti, Paul Cottu and François-Clément Bidard contributed equally to this work.

${ }^{1}$ UVSQ, Université Paris-Saclay, Saint Cloud, France

${ }^{2}$ Department of Medical Oncology, Institut Curie, Paris, France

Full list of author information is available at the end of the article
}

(c) The Author(s). 2020 Open Access This article is licensed under a Creative Commons Attribution 4.0 International License, which permits use, sharing, adaptation, distribution and reproduction in any medium or format, as long as you give appropriate credit to the original author(s) and the source, provide a link to the Creative Commons licence, and indicate if changes were made. The images or other third party material in this article are included in the article's Creative Commons licence, unless indicated otherwise in a credit line to the material. If material is not included in the article's Creative Commons licence and your intended use is not permitted by statutory regulation or exceeds the permitted use, you will need to obtain permission directly from the copyright holder. To view a copy of this licence, visit http://creativecommons.org/licenses/by/4.0/ The Creative Commons Public Domain Dedication waiver (http://creativecommons.org/publicdomain/zero/1.0/) applies to the data made available in this article, unless otherwise stated in a credit line to the data. 
(Continued from previous page)

Conclusions: This prospective registry analysis suggests that the COVID-19 mortality rate in breast cancer patients depends more on comorbidities than prior radiation therapy or current anti-cancer treatment. Special attention must be paid to comorbidities when estimating the risk of severe COVID-19 in breast cancer patients.

Keywords: SARS-CoV-2, COVID-19, Breast cancer, Outcome, Survival

\section{Background}

On December 31, 2019, the World Health Organization was informed about cases of pneumonia of unknown cause in Wuhan, China [1]. A novel coronavirus, named severe acute respiratory syndrome coronavirus 2 (SARS$\mathrm{CoV}-2$ ), was identified as the cause of coronavirus disease 2019 (COVID-19) [2]. Over the following months, the viral outbreak shifted from China to the rest of the world and was subsequently recognized as a pandemic (http://www.euro.who.int/en/health-topics/health-emerg encies/coronavirus-covid-19/news/news/2020/3/who-an nounces-covid-19-outbreak-a-pandemic). In France, the number of confirmed cases rose during early March: more than 2800 confirmed cases were officially reported on March 13, 2020, when the French hospital emergency response plan, which coordinates all hospitals, was increased to its maximum readiness level (https://www.who.int/ docs/default-source/coronaviruse/situation-reports). As of April 24, France is the 6th most severely affected country in the world (in terms of absolute numbers), with more than 21,000 official COVID-19-related deaths (https:// www.who.int/docs/default-source/coronaviruse/situationreports; https://www.who.int/emergencies/diseases/novelcoronavirus-2019/situation-reports). With about 6000 deaths, the Paris area is one of the most severely affected regions in France (https://www.santepubliquefrance.fr/ recherche/\#search=COVID\%2019\%20point\%20epidemiol ogique\&sort=date).

The first report on COVID-19 outcome in cancer patients was published on February 14 [3]: in a series of 18 Chinese patients with a history of cancer and a diagnosis of COVID-19, 7 (39\%) had to be treated in the intensive care unit (ICU) and/or died. This seminal retrospective study prompted major concerns about the risk of COVID-19 infection in cancer patients. Further studies confirmed that compared to the Chinese general population, cancer patients are at higher risk of severe COVID19 symptoms and death [3-5] (https://doi.org/10.2139/ ssrn.3558017). Cancer patients with blood, lung, or metastatic cancers were reported to have the highest frequency of severe outcome [4] (https://doi.org/10.2139/ ssrn.3558017). These retrospective reports, of limited size and restricted to patients hospitalized in Chinese hospitals, may not be fully transposable to Western healthcare systems, as suggested by a preliminary report on New Yorkers admitted to ICU [6].
Our study reports the COVID-19 features and outcomes experienced by inpatients and outpatients actively treated for breast cancer at Institut Curie hospitals $(\mathrm{ICH})$ in the Paris area, France.

\section{Methods \\ Registry}

The prospective COVID-19 registry was approved by the $\mathrm{ICH}$ institutional review board, which waived documentation of informed consent due to its observational nature. Starting from March 13, 2020, all proven or suspected COVID-19 cases were prospectively registered. Declaration of all proven or suspected cases was made mandatory by the $\mathrm{ICH}$ Director and done by any doctor or nurse to a unique email address, even if RNA test was not done or available. Emails were checked several times a day by a team of 5 doctors; all declared patients were included in the registry on the same day (day 1) and followed up. The standardized follow-up included phone calls to patients which were scheduled at days 8 , 14, and 28 and tracked in the central registry. Follow-up calls were initially given by doctors, later joined by other $\mathrm{ICH}$-qualified healthcare workers (such as genetic counselors, who received a training on COVID-19) for patients who had mild symptoms or who were recovering. More frequent and/or longer follow-up was provided whenever medically necessary. Patients hospitalized outside IC hospitals were also registered and prospectively followed. The list of patients who had an RNA test prescribed at ICH was also investigated (with no missing case identified). Data captured in the registry are displayed in Supplementary Methods 1. For this analysis, data were extracted on April 25, 2020. This report was written according to the STROBE checklist.

Breast cancer care at IC during the SARS-CoV-2 pandemic Guidance on breast cancer care during the pandemic is detailed in Supplementary Methods 2.

\section{COVID-19 diagnosis: laboratory tests and radiology SARS-CoV-2 RNA tests}

Testing was initially restricted to critically ill patients with COVID-19 symptoms, but subsequently became available to all cancer patients (including outpatients that were under active treatment) with suspected COVID-19 at the end of March 2020. Nasopharyngeal 
swabs were analyzed for SARS-CoV-2 RNA by reversetranscription polymerase chain reaction assays targeting 2 regions of the viral $\mathrm{RdRp}$ gene. All assays used in France had to be validated by the French National Reference Center (Institut Pasteur, Paris, France) (https:// www.who.int/docs/default-source/coronaviruse/realtime-rt-pcr-assays-for-the-detection-of-sars-cov-2-insti tut-pasteur-paris.pdf?sfvrsn=3662fcb6_2; https://solidari tes-sante.gouv.fr/IMG/pdf/liste-reactifs-diagnostic-rtpcr.pdf).

\section{CT scan protocol and image interpretation}

Whenever available, CT images were centrally reviewed by two senior radiologists with consensus qualitative and semiquantitative assessment. In accordance with previous reports on COVID-19 imaging [7, 8], the following patterns were sought: ground-glass opacity, crazy paving (ground-glass opacity associated with interlobular septal thickening [9]), focal consolidation, and linear consolidation. To be included in the COVID-19 population, patients with negative or not available RNA test had to display typical and newly acquired (i.e., not pre-existing on the previous CT scan) COVID-19-related lung lesions. The predominant pattern was determined for each examination. The severity (\%) of lung involvement was evaluated according to the French Society of Radiology guidelines (http://www.sfrnet.org/portal/actu/news. phtml?id=rc\%2forg $\% 2$ fsfrnet $\% 2$ fnws $\% 2$ fNews $\% 2 f 2020 \% 2$ f20200316-155630-175). The presence of lung or pleural metastases was assessed by comparison with previous CT scans. Lung radiation therapy sequelae were evaluated by semiquantitative evaluation of confluent radiologic opacities (grade 3 of the Lent-Soma scoring system [10]) affecting the right, left, or middle lobes (no involvement; $\leq 10 \%$ of lung volumes; $11-25 \%$; $\geq 26 \%$ ).

\section{Statistics}

The main study population, "COVID-19 patients," is defined as those with positive RNA test or for whom RT-PCR result was not available (or pending) but who had suggestive radiologic findings. We also report data on the subgroup of patients who had biological confirmation of COVID-19 status using RT-PCR, referred to as "RNA-positive subgroup," but did not perform statistical analyses on that subgroup. Main outcome of patients was defined as death or ICU admission. Descriptive and univariate prognostic factor analysis was performed. Two sensitivity analyses were performed: (i) using death only and (ii) using time to death or ICU admission to account for patients with partial followup. As sensitivity analyses, prognostic factor analysis of death only was performed. Due to the highly explorative nature of the report and the small number of events, no adjustment for multiple testing was applied and multivariate analysis was not done. All analyses were performed in SAS v9.4 and R software.

\section{Results \\ COVID-19 diagnosis}

From March 13, 2020, to April 25, 2020 (date of data extraction), 76 patients actively treated for breast cancer were included in the ICH COVID-19 registry. For comparison, 15,600 breast cancer patients had at least one consultation or treatment for breast cancer at one of the IC hospitals in the 4 months before lockdown (November 1, 2019, to February 28, 2020). The patient flowchart for the COVID-19 registry is displayed in Fig. 1a. RNA testing was performed in 58 patients, while CT scan was performed in 39 patients. A total of 59 patients were diagnosed with COVID-19, based on either a positive SARS-CoV-2 RNA test ( $N=41$ patients; "RNA-positive subgroup") or, in the case of negative or missing RNA test, radiologic findings ( $N=18$ patients). Seventeen patients only reported symptoms suggestive of COVID-19 that were not confirmed by RNA test and/or lung CT scan. Most patients in the subgroup who underwent both RNA testing and CT scan presented concordant results, as displayed in Fig. 1b.

\section{Patient history}

Breast cancer patient history and comorbidities are shown in Table 1. Ten of the 59 COVID-19 patients (17\%) were older than 70 . Other notable comorbidities among COVID-19 patients included hypertension (36\%), obesity (17\%), diabetes (17\%), and heart disease (14\%). The most frequent comedication in this population was corticosteroids $(22 \%$, defined as a daily intake of more than $20 \mathrm{mg}$ equivalent dose of prednisolone, excluding chemotherapy comedications). Reasons for corticosteroid intake were symptomatic brain or leptomeningeal metastasis (10\%), epiduritis (5\%), other cancer-related symptoms (5\%), and autoimmune hepatitis $(2 \%)$, respectively. All these patients have been under corticosteroids for at least 1 month. About two thirds of COVID-19 patients (and all those treated with corticosteroids) were treated for metastatic breast cancer. As shown in Table 2, ongoing anti-cancer treatments were representative of those currently administered to patients treated for early or metastatic disease, most commonly chemotherapy (49\%), followed by endocrine therapy (32\%).

\section{Features at diagnosis}

Clinical, laboratory, and radiologic features at diagnosis are displayed in Table 3. Fever and cough were the most common symptoms, observed in $46 \%$ and $37 \%$ of COVID-19 patients, respectively. Nine of the 59 patients (18\%) developed COVID-19 symptoms more than 2 days after being admitted to hospital (IC or elsewhere), 


\section{A: Patient flow}

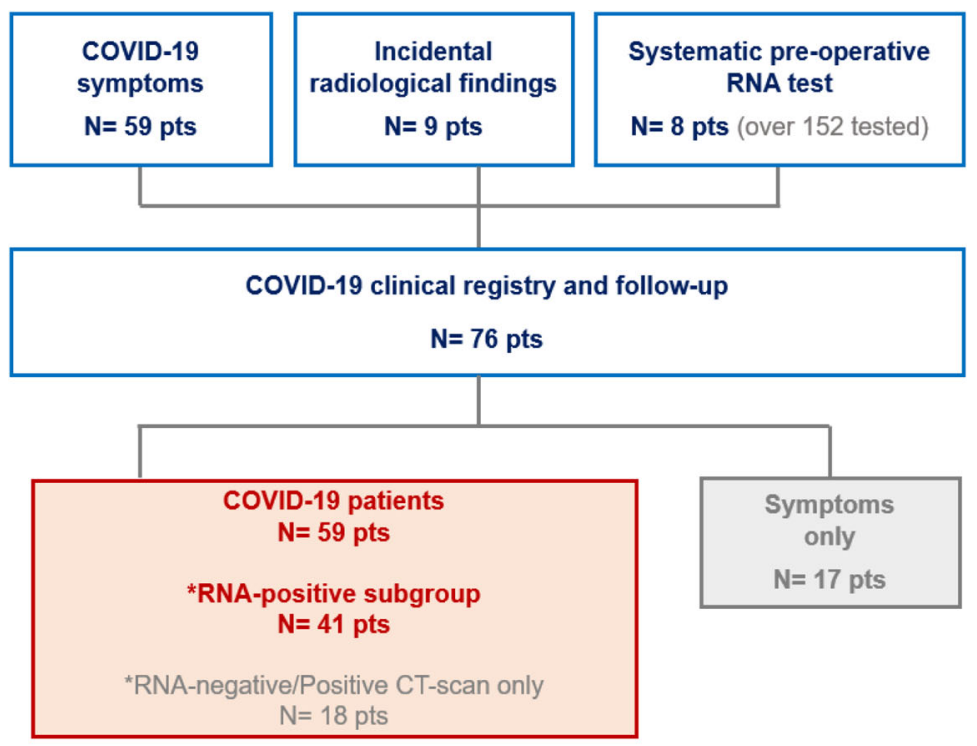

B: Relationship between clinical, laboratory and radiologic features

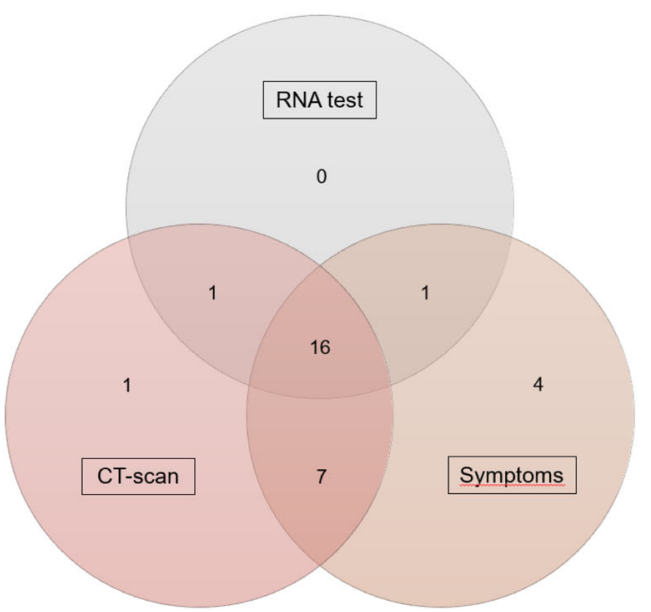

Fig. 1 Patient flow and COVID-19 testing. a Patient flow. b Relationship between clinical, laboratory, and radiologic features. Venn diagram focusing on the 30 patients with symptoms and available CT scan and RNA test results. Independence of RNA test and CT scan was rejected (Fisher's exact test, $p<0.001$ )

corresponding to the interval used to define nosocomial infections. The mean absolute lymphocyte count was normal $\left(1.5 / \mathrm{mm}^{3}\right)$. Most patients had no or limited extent of COVID-19 lung disease, as 25/28 patients (89\%) had less than $25 \%$ involvement of their lung volume. Twenty-eight CT scans were available for central review: the most common radiologic feature was ground-glass opacities, observed in 14/28 (50\%) of COVID-19 patients with CT scan at diagnosis. No significant association was observed between these characteristics or the presence of lung metastases and the extent of COVID-19 lung disease. Supplementary Figure 1 displays, for each COVID-19 patient, the prior radiation therapy fields, radiation therapy sequelae, and extent of COVID-19 lung disease. There was no association between prior radiation therapy and the extent of COVID-19 lesions ( $\leq 10 \%$ vs $>10 \%$, Fisher's exact test $p=0.69$ ).

\section{Outcome and prognostic factors}

All patient outcomes were updated 2 days prior to this analysis. Of the 59 breast cancer patients diagnosed with COVID-19, 28 (47\%) were hospitalized, while 31 (53\%) returned home. Twenty-three $(82 \%)$ of the 28 hospitalized patients received antibiotics, and 3 (11\%) received corticosteroids. No patients received hydroxychloroquine, antiviral, or immunomodulating drugs as frontline treatment at admission. The use of these 
Table 1 Patients' medical history

\begin{tabular}{|c|c|c|}
\hline & COVID-19 patients, $N$ pts/N evaluable (\%) & RNA-positive subgroup, $N$ pts/N evaluable (\%) \\
\hline \multicolumn{3}{|l|}{ Patient characteristics } \\
\hline Median age (IQR) & $58(48-68)$ & $57(48-68)$ \\
\hline Median BMI (IQR) & $26(22-30)$ & $26(22-29)$ \\
\hline \multicolumn{3}{|l|}{ Comorbidities } \\
\hline Age $>70$ years old & 10/59 (17\%) & $8 / 41(20 \%)$ \\
\hline Obesity (BMI > 30) & 10/59 (17\%) & $7 / 41(17 \%)$ \\
\hline Active smokers & $4 / 59(7 \%)$ & $3 / 41(7 \%)$ \\
\hline Chronic lung disease & $2 / 59(3 \%)$ & $1 / 41(2 \%)$ \\
\hline Diabetes & 10/59 (17\%) & $9 / 41(22 \%)$ \\
\hline Hypertension & $21 / 59(36 \%)$ & $17 / 41(42 \%)$ \\
\hline Heart disease & $8 / 59(14 \%)$ & $8 / 41(20 \%)$ \\
\hline Systemic disease & $3 / 59(5 \%)$ & 3/41 (7\%) \\
\hline Any of the above & 20/59 (34\%) & $13 / 41(32 \%)$ \\
\hline \multicolumn{3}{|l|}{ Comedications } \\
\hline Corticosteroids & $13 / 59(22 \%)$ & 9/41 (22\%) \\
\hline NSAID & $0 / 59(0 \%)$ & $0 / 41(0 \%)$ \\
\hline ACE inhibitor/ARB & $15 / 59(25 \%)$ & $13 / 41(32 \%)$ \\
\hline Anticoagulants & $8 / 59(14 \%)$ & $5 / 41(12 \%)$ \\
\hline Immunosuppressives & 1/59 (2\%) & $1 / 41(2 \%)$ \\
\hline \multicolumn{3}{|l|}{ Breast cancer } \\
\hline \multicolumn{3}{|l|}{ Subtype } \\
\hline $\mathrm{HR}+$ & $39 / 59(66 \%)$ & 29/41 (70\%) \\
\hline Triple-negative & 10/59 (17\%) & 6/41 (15\%) \\
\hline HER2+ & 10/59 (17\%) & $6 / 41(15 \%)$ \\
\hline \multicolumn{3}{|l|}{ Clinical setting } \\
\hline Neoadjuvant & $7 / 59(12 \%)$ & $7 / 41(17 \%)$ \\
\hline Adjuvant & $15 / 59(25 \%)$ & 15/41 (37\%) \\
\hline Metastatic, $<3$ prior lines & $20 / 59(34 \%)$ & $11 / 41(27 \%)$ \\
\hline Metastatic, $\geq 3$ prior lines & $17 / 59(29 \%)$ & $8 / 41(20 \%)$ \\
\hline \multicolumn{3}{|l|}{ History of radiation therapy } \\
\hline Breast/chest wall irradiation & $36 / 59(61 \%)$ & 19/41 (46\%) \\
\hline SCLN irradiation & $29 / 59(49 \%)$ & $14 / 41(34 \%)$ \\
\hline IMN irradiation & 23/59 (39\%) & $11 / 41$ (27\%) \\
\hline None & 23/59 (39\%) & $22 / 41(54 \%)$ \\
\hline \multicolumn{3}{|c|}{ Metastatic sites (in metastatic pts) } \\
\hline$<3$ sites & $22 / 37(60 \%)$ & $14 / 19(74 \%)$ \\
\hline$\geq 3$ sites & 15/37 (41\%) & $5 / 19(26 \%)$ \\
\hline Lung/pleural metastases & $16 / 37(43 \%)$ & $5 / 19(26 \%)$ \\
\hline Bone metastases & $24 / 37(65 \%)$ & $17 / 19(90 \%)$ \\
\hline Liver metastases & $11 / 37(30 \%)$ & $5 / 19(26 \%)$ \\
\hline CNS metastases & $7 / 37(19 \%)$ & $3 / 19(16 \%)$ \\
\hline Other sites & $16 / 37(43 \%)$ & 7/19 (37\%) \\
\hline Total & $N=59$ & $N=41$ \\
\hline
\end{tabular}

Corticosteroids refer to a chronic daily dose equivalent to $\geq 20 \mathrm{mg}$ of prednisolone (chemotherapy premedication not taken into account). Systemic diseases: 2 patients had a rheumatoid arthritis and 1 patient had an autoimmune hepatitis. BMI body mass index, NSAID non-steroidal antiinflammatory drugs, $A C E$ angiotensin-converting enzyme, $A R B$ angiotensin II receptor blockers, HR+ hormone receptor-positive, Triple-negative HER2and hormone receptor-negative, HER2+ HER2-positive, CNS central nervous system, SCLN supraclavicular lymph nodes, IMN internal mammary nodes 
Table 2 Ongoing treatments

\begin{tabular}{|c|c|c|}
\hline & COVID-19 patients, N pts/N evaluable (\%) & RNA-positive subgroup, $N$ pts/N evaluable (\%) \\
\hline Early breast cancer patients & $N=22$ & $N=22$ \\
\hline Surgery* & $3 / 22(14 \%)$ & $3 / 22(14 \%)$ \\
\hline Chemotherapy & $8 / 22(36 \%)$ & $8 / 22(36 \%)$ \\
\hline Epirubicin and cyclophosphamide & $5 / 22(23 \%)$ & $5 / 22(23 \%)$ \\
\hline Paclitaxel/docetaxel & $2 / 22(9 \%)$ & $2 / 22(9 \%)$ \\
\hline Radiation therapy & $2 / 22(9 \%)$ & $2 / 22(9 \%)$ \\
\hline Endocrine therapy & $4 / 22(18 \%)$ & $4 / 22(18 \%)$ \\
\hline Anti-estrogens & $3 / 22(14 \%)$ & $3 / 22(14 \%)$ \\
\hline Aromatase inhibitors & $1 / 22(4 \%)$ & $1 / 22(4 \%)$ \\
\hline Targeted therapy & $3 / 22(14 \%)$ & $3 / 22(14 \%)$ \\
\hline Trastuzumab & $2 / 22(9 \%)$ & $2 / 22(9 \%)$ \\
\hline Pertuzumab & $1 / 22(4 \%)$ & $1 / 22(4 \%)$ \\
\hline Trastuzumab emtansine & $1 / 22(4 \%)$ & $1 / 22(4 \%)$ \\
\hline None & $6 / 22(27 \%)$ & $6 / 22(27 \%)$ \\
\hline Pending surgery & $5 / 22(23 \%)$ & $5 / 22(23 \%)$ \\
\hline Pending radiation therapy & $1 / 22(4 \%)$ & $1 / 22(4 \%)$ \\
\hline Combination of any treatment & $3 / 22(14 \%)$ & $3 / 22(14 \%)$ \\
\hline Metastastic breast cancer patients & $N=37$ & $N=19$ \\
\hline Surgery* & $0(0 \%)$ & $0(0 \%)$ \\
\hline Chemotherapy & $21 / 37(57 \%)$ & $10 / 19(53 \%)$ \\
\hline Capecitabine & $7 / 37(19 \%)$ & $4 / 19(21 \%)$ \\
\hline Paclitaxel/docetaxel & 6/37 (16\%) & $3 / 19(16 \%)$ \\
\hline Epirubicin and cyclophosphamide & $1 / 37(3 \%)$ & $0(0 \%)$ \\
\hline Vinorelbine & $2 / 37(5 \%)$ & $0(0 \%)$ \\
\hline Eribulin & $1 / 37(3 \%)$ & $1 / 19(5 \%)$ \\
\hline Gemcitabine & $2 / 37(5 \%)$ & $1 / 19(5 \%)$ \\
\hline Carboplatin & $3 / 37(8 \%)$ & $1 / 19(5 \%)$ \\
\hline Intrathecal chemotherapy & 2/37 (5\%) & 2/19 (10\%) \\
\hline Radiation therapy & $2 / 37(5 \%)$ & $2 / 19(10 \%)$ \\
\hline Endocrine therapy & $15 / 37(40 \%)$ & $7 / 19(37 \%)$ \\
\hline Anti-estrogens & $3 / 37(8 \%)$ & $1 / 19(5 \%)$ \\
\hline Aromatase inhibitors & $11 / 37(30 \%)$ & 6/19 (32\%) \\
\hline Selective estrogen receptor degrader & $1 / 37(3 \%)$ & $0(0 \%)$ \\
\hline Targeted therapy & $16 / 37(43 \%)$ & $7 / 19(37 \%)$ \\
\hline CDK4/6 inhibitor & 9/37 (24\%) & $5 / 19(26 \%)$ \\
\hline Trastuzumab & $5 / 37(13 \%)$ & $2 / 19(10 \%)$ \\
\hline Pertuzumab & 4/37 (11\%) & $2 / 19(10 \%)$ \\
\hline Everolimus** & $2 / 37(5 \%)$ & $0(0 \%)$ \\
\hline Immunotherapy & $0(0 \%)$ & $0(0 \%)$ \\
\hline Combination of any treatment & $21 / 37(57 \%)$ & 8/19 (42\%) \\
\hline None & $1 / 37(3 \%)$ & $1 / 19(5 \%)$ \\
\hline Total & $N=59$ & $N=41$ \\
\hline
\end{tabular}

Listed treatments were those ongoing within 30 days before COVID-19 diagnosis

*Ongoing surgery includes 30 days from surgery

${ }^{*}$ As recommended, patients stopped everolimus at the beginning of the pandemic 
Table 3 Clinical, laboratory, and radiologic features at first examination

\begin{tabular}{|c|c|c|}
\hline & COVID-19 patients, N pts/N evaluable (\%) & RNA-positive subgroup, $N$ pts/N evaluable (\%) \\
\hline \multicolumn{3}{|l|}{ Clinical examination } \\
\hline Fever $\left(\geq 38.0^{\circ} \mathrm{C}\right)$ & $27 / 59(46 \%)$ & $21 / 41(51 \%)$ \\
\hline Cough & $22 / 59(37 \%)$ & 18/41 (44\%) \\
\hline Dyspnea & $17 / 59(29 \%)$ & 10/41 (24\%) \\
\hline Decreased saturation $(<96 \%)$ & $7 / 59(12 \%)$ & $5 / 41(12 \%)$ \\
\hline Gl disorders & $6 / 59(10 \%)$ & $5 / 41(12 \%)$ \\
\hline Headache & $3 / 59(5 \%)$ & $3 / 41(7 \%)$ \\
\hline Anosmia/dysgeusia & $5 / 59(8 \%)$ & $4 / 41(10 \%)$ \\
\hline Possible nosocomial infection & 9/59 (15\%) & $8 / 41(20 \%)$ \\
\hline \multicolumn{3}{|l|}{ Laboratory parameters } \\
\hline Neutrophil count: mean (IQR) (G/L) & $4.0(2.0-5.1), N=49$ & $4.3(2.0-5.0), N=31$ \\
\hline Lymphocyte count: mean (IQR) (G/L) & $1.5(0.8-1.9), N=49$ & $1.5(1.3-3.9), N=31$ \\
\hline $\mathrm{LDH}>\mathrm{ULN}$ & $11 / 12(92 \%)$ & 4/4 (100\%) \\
\hline \multicolumn{3}{|l|}{ CT scan available for central review } \\
\hline \multicolumn{3}{|l|}{ Extent of lesions (\% of lung volume) } \\
\hline No lesion & $2 / 28(7 \%)$ & 2/14 (14\%) \\
\hline$<10 \%$ & $11 / 28(39 \%)$ & $2 / 14(14 \%)$ \\
\hline $10-25 \%$ & $12 / 28(42 \%)$ & $8 / 14(57 \%)$ \\
\hline $26-50 \%$ & 2/28 (7\%) & $1 / 14(7 \%)$ \\
\hline $51-75 \%$ & $1 / 28(4 \%)$ & $1 / 14(7 \%)$ \\
\hline$>75 \%$ & 0/28 (0\%) & 0/14 (0\%) \\
\hline \multicolumn{3}{|l|}{ Predominant type of lesion } \\
\hline No lesion & $2 / 28(7 \%)$ & $2 / 14(14 \%)$ \\
\hline Ground-glass opacities & $14 / 28(50 \%)$ & $7 / 14(50 \%)$ \\
\hline Crazy paving & $4 / 28(14 \%)$ & $1 / 14(7 \%)$ \\
\hline Focal consolidation & $7 / 28(25 \%)$ & 3/14 (22\%) \\
\hline Linear consolidation & $1 / 28(0 \%)$ & $1 / 14(7 \%)$ \\
\hline \multicolumn{3}{|l|}{ Loco-regional radiation therapy } \\
\hline No radiation therapy & $9 / 28(32 \%)$ & 8/14 (57\%) \\
\hline No sequela (0\%) & $8 / 28(29 \%)$ & 4/14 (29\%) \\
\hline Sequela extent: 1-10\% of lung volume & $9 / 28(32 \%)$ & $2 / 14(14 \%)$ \\
\hline Sequela extent: $11-25 \%$ of lung volume & $2 / 28(7 \%)$ & 0/14 (0\%) \\
\hline Sequela extent: $>25 \%$ of lung volume & 0/28 (0\%) & $0 / 14(0 \%)$ \\
\hline
\end{tabular}

Nosocomial infection refers to a new infection diagnosed $>2$ days after admission to hospital. Gl gastrointestinal, ULN upper limit of normal

putative treatments, which were available whenever necessary throughout the patient's stay in hospital, was not always available for patients hospitalized outside $\mathrm{ICH}$.

None of the 17 symptom-only patients had to be hospitalized. The flow of COVID-19 patients during the course disease is shown in Fig. 2. Four patients were transferred to ICU at diagnosis or during hospitalization. As of April 24, 45 (76\%) of the 59 COVID-19 patients were considered to be either recovering or cured. The outcome of 10 (17\%) patients remains undetermined (most recent cases with limited follow-up), while 4 (6.7\%) patients died: 2 patients were receiving later lines of treatment for metastatic breast cancer (these patients were not transferred to ICU), 1 patient had recently started first-line endocrine therapy combined with palbociclib, and 1 patient was receiving neoadjuvant chemotherapy. Noteworthy, this last patient was treated with an anti-CD80/86 antibody (regulating CTLA-4 signaling). Further details on the history of the four deceased patients are available in Table 4. 


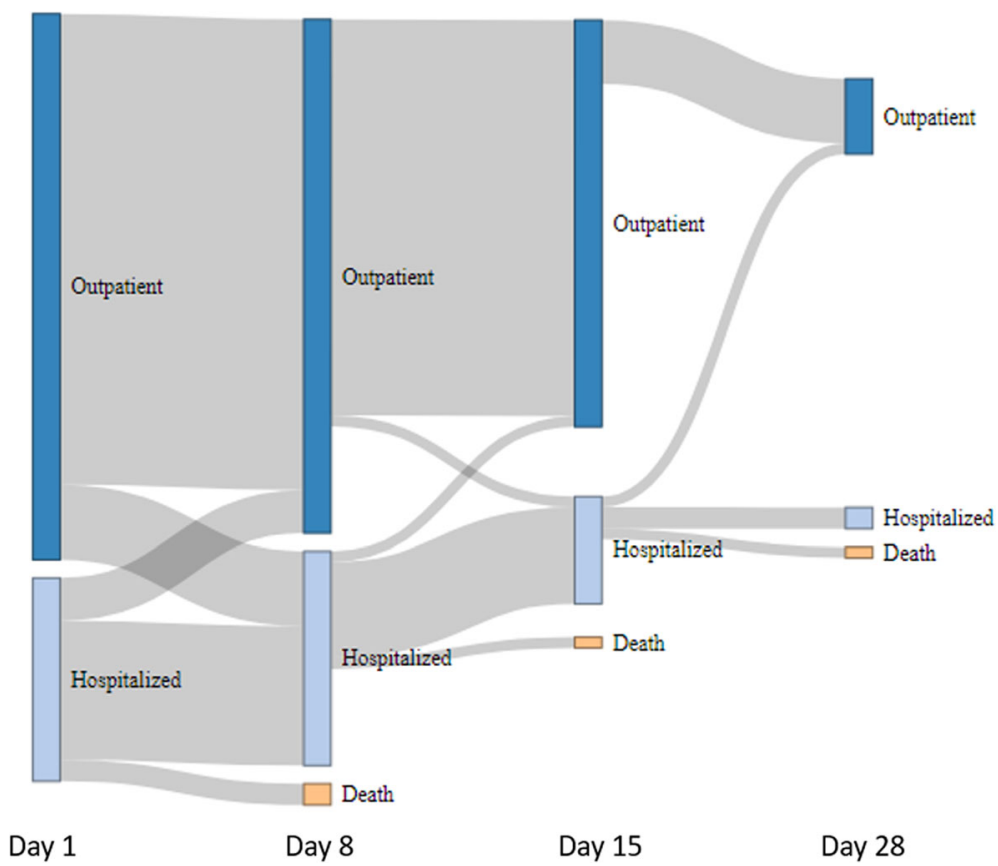

Fig. 2 COVID-19 patients' trajectory. Follow-up consisted in clinical evaluation by phone calls scheduled at days 8,14 , and 28

An exploratory analysis of factors associated with either ICU admission or death in the COVID-19 population showed that among all factors listed in Tables 1,2 , and 3, only age $>70$ years and hypertension were significantly associated with COVID-19 severity (both $p<0.05$ ). More specifically, the ongoing systemic treatment type (Supplementary Table 1), lymphopenia $(<0.5 \mathrm{G} / \mathrm{L})$, neutropenia $(<1 \mathrm{G} / \mathrm{L})$, and use of angiotensin-converting enzyme inhibitors or angiotensin receptor blockers had no significant prognostic impact (all $p$ value $>0.6$ ). Age and hypertension remained as prognostic factors in the subgroup of RNA test-positive patients except that hypertension was of borderline significance. Same statistical conclusions were obtained with the analyses of time to death or ICU admission.

\section{Discussion}

The SARS-CoV-2 outbreak is the first viral pandemic affecting cancer patients and oncology teams. To the best of our knowledge, this is the first report on COVID-19 diagnosis, signs, and outcome in breast cancer patients.

While 15,600 patients were actively treated for breast cancer at Institut Curie hospitals over the 4 months prior to the pandemic, only 59 were diagnosed with COVID-19 by either RNA test or CT scan. A recent study estimated that more than $10 \%$ of inhabitants of the greater Paris area have been infected by the SARSCoV-2 virus (https://hal-pasteur.archives-ouvertes.fr/pasteur-02548181). While our study cannot determine the incidence of COVID-19 infection among breast cancer patients, the small number of diagnosed cases suggests that breast cancer patients do not appear to be at higher risk than the general population. This apparent low incidence could possibly be attributed to much stricter application of social distancing procedures by cancer patients, who had been informed that they may be at higher risk of severe COVID-19 infection. Prophylactic changes implemented in breast cancer care (e.g., postponement of all non-mandatory visits to $\mathrm{ICH}$, changes in medical treatments) may also have contributed to further reduce the risk of SARS-CoV-2 infection. A limitation of our study is that some patients may have been treated by their family physicians or referred to local hospitals, without any notification to $\mathrm{ICH}$. Although no data was available to compare COVID-19 patients to the other breast cancer patients seen at $\mathrm{ICH}$, rates of high BMI and hypertension in our COVID-19 patient cohort were very similar to those reported in a recent prospective large-scale report on French breast cancer patients [11], suggesting that these comorbidities do not increase the risk of COVID-19. Our analyses showed that breast cancer patients have similar clinical and radiologic features of COVID-19 to those previously described in other reports on non-cancer COVID-19 patients. Importantly, we found no trend in favor of a relationship between a history of breast and lymph node radiation therapy, radiation therapy sequela, and radiologic extent of disease or outcome. Thrombotic, cardiovascular, microvascular, and dermatological events were not 
Table 4 Description of COVID-19-related deaths

Patient \#1 was a 69-year-old woman with a history of diabetes, hypertension, hypertrophic cardiomyopathy, and rheumatoid arthritis treated by abatacept (a CTLA-4 immunoglobulin). She was diagnosed with stage IIB triple-negative breast cancer in February 2020 and started neoadjuvant chemotherapy (epirubicin and cyclophosphamide) in March. Three days after the first cycle, she was referred to the emergency room (ER) with chest pain, fever, and lung infection (day 1). SARS-CoV-2 infection was diagnosed based on positive RNA PCR and chest CT scan. She was admitted to ICU for acute respiratory distress on day 7 , treated with antibiotics, antiviral therapy (chloroquine and lopinavir/ritonavir), and endotracheal intubation and ventilation. She died 19 days later (day 26).

Patient \#2 was a 44-year-old patient with no relevant medical history, diagnosed with de novo stage IV hormone-sensitive breast cancer (node, bone, and hepatic metastases, with $4 \mathrm{~N}$ cytolysis) in February 2020. She received a first-line combination of CDK4/6 inhibitor, aromatase inhibitor, and complete ovarian function suppression. On day 17 of her first month of treatment, she was referred to the ER for asthenia, dyspnea, grade IV thrombocytopenia (14 G/L), and grade IV neutropenia $(0.2 \mathrm{G} / \mathrm{L})$. She was diagnosed with SARS-CoV-2 lung infection complicated by thrombotic microangiopathy, based on positive RNA test, chest CT scan, and laboratory data. She was treated symptomatically, including antibiotics, and was not transferred to ICU due to her metastatic disease and major multiple organ failure. She died 8 days after ER admission.

Patient \#3 was a 78-year-old woman with a history of hypertension. She had been treated since November 2013 for stage IV hormonesensitive breast cancer (lung and bone metastases). In March 2020, she received two cycles of weekly paclitaxel as second-line chemotherapy. Five days after the last injection, she was referred to the ER with dyspnea and hypoxia. SARS-CoV-2 infection was diagnosed based on a typical chest $C T$ scan with extensive consolidation involving approximately $50 \%$ of the lungs. PCR RNA test was negative. Hydroxychloroquine and antibiotics were rapidly initiated on day 1 , but the patient was not transferred to ICU due to her limited oncological life

expectancy. She died on day 4.

Patient \#4 was an 80-year-old woman treated for metastatic hormonesensitive breast cancer (bone metastasis only) since February 2016. Since January 2020, after tumor progression, systemic therapies were stopped in favor of best supportive care. She had been hospitalized for tumor-related symptoms since February 2020. In late March, she presented signs of lung infection, followed by acute respiratory distress. Nosocomial SARS-CoV-2 infection was diagnosed based on positive RNA PCR and chest CT scan with ground-glass opacities involving approximately $20 \%$ of the lungs. Palliative symptomatic treatments with nasal oxygen therapy were initiated, and the patient died 12 days after onset of the first symptoms.

recorded, as their association with COVID-19 was not fully recognized when the registry was set up.

In terms of COVID-19 outcome, we observed a nonnegligible mortality rate of $6.7 \%(4 / 59)$ among breast cancer patients diagnosed with COVID-19, with a higher mortality rate of $9.7 \%(4 / 41)$ in the RNA-positive subgroup. As of April 26, the reported mortality rate among RNA-positive patients in the general population ranges from $18.2 \%$ in France to $5.6 \%$ in the USA and $3.7 \%$ in Germany (https://www.who.int/docs/default-source/coronaviruse/situation-reports). However, these percentages reflect more testing policy more than true differences in mortality rates. As in the general population, the true infection and mortality rates could subsequently be determined by serology tests detecting an immune response to SARS-CoV-2. Nevertheless, on univariate analysis, age and hypertension were associated with disease severity rather than the extent of disease or ongoing cancer therapy. More specifically, we found no statistical relationship between ongoing chemotherapy and outcome. Overall, our data suggest that breast cancer patients share the same risk factors for severe COVID-19 as the general population. Strikingly, the only early breast cancer patient who died was concomitantly treated for a systemic disease by a CTLA-4 signaling modulator, suggesting that breast cancer per se is not a major contributor to COVID-19 mortality. Limitations of this analysis include the limited number of patients, a potential under-declaration due to the difficulty in identifying COVID-19 cases in outpatients who may have been referred to other hospitals. A longer follow-up of this registry may help defining more precisely the outcome of breast cancer patients with COVID-19.

\section{Conclusions}

While lockdown lifting procedures are being discussed in most Western countries, this first report on breast cancer patients suggests that comorbidities (apart from breast cancer) should be the primary focus of attention to define patients at high risk. Further studies devoted to breast cancer patients will help to define breast cancer care for the following months, until preventive treatments, such as a vaccine, have been found.

\section{Supplementary information}

Supplementary information accompanies this paper at https://doi.org/10. 1186/s13058-020-01293-8.

\section{Additional file 1}

\section{Acknowledgements}

Institut Curie Breast Cancer and COVID Group: Aurélia Alimi, Muriel Belotti, Okba Bensaoula, Ophélie Bertrand, Geoffroy Bilger, Etienne Brain, Hervé Brisse, Bruno Buecher, Laetitia Chanas, Caroline Chapus, Isabelle CharlesMassar, Pascal Chérel, Gilles Créhange, Christelle Colas, Hélène Delhomelle, Thomas Frederic-Moreau, Emmanuelle Fourme, Pierre Fumoleau, Marion Gauthier-Villars, Olivier Lantz, Sophie Lassalle, Marine Le Mentec, Florence Lerebours, Delphine Loirat, Matthieu Minsat, Pauline Moreau, Antoine de Pauw, Maël Priour, Fabien Reyal, Roman Rouzier, Mary Saad, Claire Saule, Clara Sebbag, Dominique Stoppa-Lyonnet, Anne Tardivon, Silvia Takanen, Dominique Vanjak, Marie-Charlotte Villy, Anne Vincent-Salomon, and Mathilde Warcoin.

\section{Authors' contributions}

MF, TR, CB, SD, AN, AB, VS, YK, LC, and JYP contributed to the data collection and interpretation. $L B$ and $P C$ set up the registry and contributed to the data interpretation. LC contributed to the manuscript writing. PV and FCB

collected the data, contributed to the analysis, and wrote the manuscript. XP set up the registry, performed the statistical analyses, and contributed to the writing of the manuscript. All authors have read and approved the final manuscript.

\section{Funding}

Institut Curie, Université de Versailles Saint Quentin, and Université ParisSaclay (no grant number applicable). 


\section{Availability of data and materials}

The datasets generated and analyzed during this study are not publicly available due to French HIPAA (birthdate, admission date, discharge date, date of death), but are available from the corresponding author on reasonable request.

\section{Ethics approval and consent to participate}

The COVID-19 registry was approved by the Institut Curie institutional review board, which waived documentation of informed consent due to the observational nature of the registry.

\section{Consent for publication}

Not applicable.

\section{Competing interests}

The authors declare that they have no competing interests.

\section{Author details}

'UVSQ, Université Paris-Saclay, Saint Cloud, France. ${ }^{2}$ Department of Medical Oncology, Institut Curie, Paris, France. ${ }^{3}$ Department of Medical Oncology, Institut Curie, Saint Cloud, France. ${ }^{4}$ Department of Drug Development and Innovation, Institut Curie, Paris, France. ${ }^{5}$ Department of Radiology, Institut Curie, Paris, France. ${ }^{6}$ Department of Surgical Oncology, Institut Curie, Paris, France. 'Department of Radiation Oncology, Institut Curie, Paris, France. ${ }^{8}$ Université de Paris, Paris, France. ${ }^{9}$ INSERM U900 STAMPM Team, Saint Cloud, France.

Received: 29 April 2020 Accepted: 12 May 2020

Published online: 28 May 2020

\section{References}

1. Wu F, Zhao S, Yu B, Chen YM, Wang W, Song ZG, Hu Y, Tao ZW, Tian JH, Pei $Y Y$, et al. A new coronavirus associated with human respiratory disease in China. Nature. 2020;579(7798):265-9.

2. Lu R, Zhao X, Li J, Niu P, Yang B, Wu H, Wang W, Song H, Huang B, Zhu N, et al. Genomic characterisation and epidemiology of 2019 novel coronavirus: implications for virus origins and receptor binding. Lancet. 2020;395(10224):565-74.

3. Liang W, Guan W, Chen R, Wang W, Li J, Xu K, Li C, Ai Q, Lu W, Liang H, et al. Cancer patients in SARS-CoV-2 infection: a nationwide analysis in China. Lancet Oncol. 2020:21(3):335-7.

4. Yu J, Ouyang W, Chua MLK, Xie C. SARS-CoV-2 transmission in patients with cancer at a tertiary care hospital in Wuhan, China. JAMA Oncol. 2020. https://doi.org/10.1001/jamaoncol.2020.0980. [Epub ahead of print].

5. Zhang L, Zhu F, Xie L, Wang C, Wang J, Chen R, Jia P, Guan HQ, Peng L, Chen $Y$, et al. Clinical characteristics of COVID-19-infected cancer patients: a retrospective case study in three hospitals within Wuhan, China. Ann Oncol. 2020. https://doi.org/10.1016/j.annonc.2020.03.296. [Epub ahead of print].

6. Miyashita H, Mikami T, Chopra N, Yamada T, Chernyavsky S, Rizk D, Cruz C. Do patients with cancer have a poorer prognosis of COVID-19? An experience in New York City. Ann Oncol. 2020. https://doi.org/10.1016/j. annonc.2020.04.006. [Epub ahead of print].

7. Salehi S, Abedi A, Balakrishnan S, Gholamrezanezhad A, et al. AJR Am J Roentgenol. 2020:1-7.

8. Huang G, Gong T, Wang G, Wang J, Guo X, Cai E, Li S, Li X, Yu Y, Lin L. Timely diagnosis and treatment shortens the time to resolution of coronavirus disease (COVID-19) pneumonia and lowers the highest and last CT scores from sequential chest CT. AJR Am J Roentgenol. 2020:1-7.

9. Hansell DM, Bankier AA, MacMahon H, McLoud TC, Muller NL, Remy J. Fleischner Society: glossary of terms for thoracic imaging. Radiology. 2008; 246(3):697-722.

10. Claude L, Perol D, Ginestet C, Falchero L, Arpin D, Vincent M, Martel I, Hominal S, Cordier JF, Carrie C. A prospective study on radiation pneumonitis following conformal radiation therapy in non-small-cell lung cancer: clinical and dosimetric factors analysis. Radiother Oncol. 2004;71(2): 175-81.

11. Kabore EG, Guenancia C, Vaz-Luis I, Di Meglio A, Pistilli B, Coutant C, Cottu $P$, Lesur A, Petit T, Dalenc F, et al. Association of body mass index and cardiotoxicity related to anthracyclines and trastuzumab in early breast cancer: French CANTO cohort study. PLoS Med. 2019;16(12):e1002989.

\section{Publisher's Note}

Springer Nature remains neutral with regard to jurisdictional claims in published maps and institutional affiliations.

\section{Ready to submit your research? Choose BMC and benefit from:}

- fast, convenient online submission

- thorough peer review by experienced researchers in your field

- rapid publication on acceptance

- support for research data, including large and complex data types

- gold Open Access which fosters wider collaboration and increased citations

- maximum visibility for your research: over $100 \mathrm{M}$ website views per year

At BMC, research is always in progress.

Learn more biomedcentral.com/submissions 